\title{
Entre a história e a liberdade
}

\author{
Durval Muniz de Albuquerque Júnior**
}

O mais recente livro publicado pela historiadora Margareth Rago possui os mesmos méritos de suas obras anteriores: livro de agradável leitura por seu estilo literário, embasado em rica $e$ inédita documentação, aporte teórico inovador e instigante, trata de um tema pouco abordado por nossa historiografia e que é de muito interesse e relevância para o debate político e cultural no mundo contemporâneo. Creio, no entanto, que este texto apresenta algumas particularidades que o fazem se destacar em relação aos trabalhos que já conhecemos desta pesquisadora: este livro nasceu de uma intensa convivência de amizade entre duas mulheres de gerações e países diferentes, identificadas pela luta em defesa da liberdade e da transformação da sociedade e da condição histórica e social das mulheres, é, pois, um texto distante de ser uma realização fria da razão e do método acadêmico, é uma obra feita a partir do afeto e da paixão, que transpira em cada página a admiração e o carinho que surgiu entre a historiadora e o objeto de sua pesquisa, a militante anarquista italiana, radicada no Uruguai, Luce Fabbri, cuja vida e pensamento pode conhecer após longos dias de entrevistas, de alguns anos de relacionamento constante e de consulta sistemática à biblioteca particular daquela que foi uma das mais importantes militantes e teóricas anarquistas do século passado.

Praticamente desconhecida fora do limitado círculo dos que se dedicam a pesquisar a história do anarquismo ou dos que com

\footnotetext{
* RAGO, Margareth. Entre a história e a liberdade: Luce Fabbri e o anarquismo contemporâneo. São Paulo, UNESP, 2001. Recebida para publicação em setembro de 2001.

* Universidade Federal da Paraíba - Campus II.
} 


\section{Entre a história e a liberdade}

ele se identificam em nosso país, Luce Fabbri dedicou toda sua vida de professora universitária à reflexão sobre uma das questões mais instigantes para o ser humano que é a da liberdade e da possibilidade de se estabelecer uma forma de organização social onde esta preocupação seja predominante. Pensar a liberdade e viver de forma libertária foi o que moveu a vida desta mulher, que procurou não ocupar o lugar tradicionalmente reservado às mulheres pela sociedade patriarcal. Fez da vida pública o seu lugar e da militância política e cultural uma forma de se inserir na história, de se tornar história, saindo da obscuridade do privado e do doméstico. Este talvez seja o maior mérito do texto, abordar a relação entre a vida individual de uma mulher e as mudanças históricas que se deram ao longo de quase um século, onde modificações substanciais ocorreram não só na sociedade ocidental, como na uruguaia em particular, no que tange, principalmente ao papel do feminino nas relações de gênero e nos acontecimentos históricos.

A biografia, vista até recentemente com muito preconceito pelos historiadores, foi considerada como uma forma ultrapassada de se fazer a história, como um gênero típico de uma historiografia positivista e de uma história elitista e louvaminheira que teria predominado no século XIX, gênero que a nova história viera superar seja em sua vertente marxista, seja em sua vertente francesa dos Annales. Agora ao historiador só deveria interessar os grandes processos, as estruturas, as relações e identidades de classes, sendo o indivíduo um mero reflexo do que se passava nos processos coletivos da sociedade. Com isso, a biografia foi um gênero historiográfico que ficou entregue até recentemente, em nosso país, a jornalistas, escritores e outros profissionais, que entre outros tiveram o mérito de deixar patente o quanto a vida de um indivíduo pode ser um foco de onde se pode iluminar os processos históricos de um dado período, introduzindo novos matizes, complexificando e trazendo a tona conflitos, contradições e projetos históricos que ficaram à margem do que se costuma apresentar, na história oficial em todas as suas versões, como o 
caminho percorrido pela história. A partir das reflexões trazidas para nós historiadores pelos filósofos da diferença - Michel Foucault, Gilles Deleuze, Félix Guattari - pela microhistória e pela historiografia da vida privada e de gênero pudemos revalorizar o papel dos indivíduos e das subjetividades na construção da história, sendo recolocada a questão de como se relacionam indivíduos e sociedade e reposta a questão da liberdade do indivíduo frente ao Estado e às instituições sociais, tão discutida pelo pensamento anarquista. O título do livro deixa claro que é esta a preocupação central do texto e a coloca como uma interrogação para o nosso próprio tempo e para o próprio conjunto dos profissionais da história, dando ao texto uma importância para as próprias reflexões teóricas e metodológicas em nosso campo.

Se, como diz Luce, a história serve para ensinar a nadar, o texto de história não fala apenas de um passado ou de um indivíduo já morto. Recoloca este passado como problema para o presente, relançando as questões que este passado e que aqueles indivíduos se colocaram, as respostas que conseguiram elaborar, os impasses, as controvérsias, os conflitos vivenciados, as lutas que se travaram naquele tempo e por aquelas pessoas, para que nós no presente tentemos encontrar novas respostas $e$ possamos refletir criticamente sobre nossa própria condição, desnaturalizando-a, percebendo-a como fruto de um processo conflituoso e contraditório onde não existe destino ou sentido obrigatório, mas só possibilidades e projetos a serem alcançados, onde o amanhã é incerto e é esta incerteza que o faz belo $e$ desafiador. A vida de Luce Fabbri e a sua relação com o tempo, com seu tempo; sua busca incessante por pensar, viver e realizar a liberdade na história e, como história, faz do livro de Margareth leitura obrigatória para quem quer também pensar, viver e realizar libertariamente sua história e a história de seu tempo.

Através do olhar de Luce Fabbri e de Margareth, o leitor poderá entrar em contato com uma das mais importantes vertentes do pensamento revolucionário dos dois últimos séculos e 
com sua particular visão da história, da liberdade, da sociedade, da revolução, da política, da democracia, do poder, do Estado, da família, da cultura, da linguagem, das relações de gênero, das relações afetivas e sexuais. As experiências anarquistas de construção de um outro tipo de sociedade são pouco conhecidas em nosso país, já que foram duplamente derrotadas e desvalorizadas, seja pelos discursos e pela historiografia burguesa, de direita, seja pelos discursos e pela historiografia socialista ou comunista, de esquerda. O silenciamento da própria história do anarquismo no Brasil só começou a ser desfeito a partir do final dos anos setenta, para o qual contribuiu outra importante obra de Margareth Rago, o já clássico Do Cabaré ao Lar. Agora, neste seu novo livro, Margareth nos traz um aspecto pouco abordado por nossa historiografia sobre o anarquismo, que é o das próprias formulações teóricas e filosóficas que esta forma de pensamento político construiu ao longo dos últimos dois séculos.

Através do pensamento de Luce Fabbri, expresso em inúmeros artigos, livros, poemas, ensaios, cartas, manifestos, panfletos, podemos entrar em contato com outros importantes teóricos e pensadores anarquistas. Podemos, através do seu olhar, entrar em contato com acontecimentos decisivos da história do anarquismo, do movimento operário e revolucionário de esquerda, do século XX. Podemos acompanhar a luta ideológica no interior das próprias esquerdas e o embate destas com o nazifascismo. Fascismo que é objeto de umas das mais argutas reflexões de Luce, que o localiza não apenas como um partido ou um fenômeno histórico datado, mas como uma forma de subjetividade, uma forma de pensar e se colocar no mundo, que passa pelas individualidades e está presente nas relações interpessoais, os microfascismos de que nos fala Guattari, que já aparece não só teorizado, mas vivenciado por esta mulher extraordinária. Fascismo de Mussolini na Itália, mas também das ditaduras militares latino-americanas dos anos setenta e oitenta. Fascismo dos nacionalistas espanhóis, que derrotam em um dos maiores banhos de sangue da história contemporânea, 
estranhamente muito pouco abordado em nossos livros e cursos de história, uma das mais radicais e inovadoras experiências revolucionárias que ocorreu durante a Guerra Civil naquele país, onde se procurou conjugar de uma nova forma a relação entre história e liberdade, onde se experimentou a autogestão das fábricas, a coletivização das terras, a descentralização da administração em comunas federadas, a adoção do amor livre, do direito ao aborto, a abolição da obrigatoriedade do matrimônio para a legitimação dos filhos, que sempre nos foram apresentadas como utopias a se realizar num futuro distante, mas que foi vivido, mesmo que tenha sido de forma romântica ou alucinada, como costumam apresentar seus críticos, por um povo, já nos anos trinta. Povo que em nome deste sonho lutou e morreu aos milhares, embora saibamos que nem todos os que lutaram nas hostes republicanas partilhassem dos mesmos ideais e que as dissensões internas muito intensas foram uma das causas da derrota. Luce nos apresenta argutas reflexões sobre estes fatos $e$ rememora sua participação $e$ de muitos companheiros $e$ companheiras nestes acontecimentos, nos apresentando uma versão sempre nascida de uma prévia e demorada reflexão, o que não significa que estas sejam imparciais, são radicalmente parciais, como ela mesma admite.

Convido, pois, todos a partilharem a vida e o pensamento desta que pode ser vista também como um testemunho de como as relações de gênero e o lugar da mulher na sociedade foi alterado profundamente neste século que acaba de terminar e da importância que as práticas e o pensamento anarquista teve $e$ continua tendo para este acontecimento. A vida de Luce e suas reflexões acerca do feminismo e do feminino nos ajudam a perceber a relevância da luta das mulheres para as transformações históricas e sociais no século $\mathrm{XX}$ e deixam ver as próprias contradições e impasses nesta luta. Permitem-nos verificar como uma importante militante política avalia o feminismo e sua importância para a vida das mulheres, o que faz nem sempre de forma muito elogiosa, já que atenta para o que chama de 
Entre a história e a liberdade

conteúdo de classe do feminismo dos anos vinte e trinta tece críticas ao que considera limites do movimento. Enfim, o livro de Margareth Rago traz para o debate contemporâneo todos estes temas que continuam nos apaixonando, que continuam sendo temas de nossas preocupações acadêmicas e políticas, enriquecidos agora pela visão que emerge do encontro destas duas mulheres, de duas subjetividades atravessadas pela paixão pela história e pela liberdade, pela paixão de fazer a história da liberdade em seu inacabável acontecer cotidiano, pela paixão de fazer a liberdade acontecer na história todos os dias e em todas as relações. 